\title{
СИНТЕЗ НОВЫХ ПОЛИМЕРОВ НА ОСНОВЕ НИТРАТА ЦЕЛЛЮЛОЗЫ
}

\author{
(ㄱ) С.М. Романова, В.И. Трескова"** Р.З. Гильманов, М.В. Хузеев, А.Г. Засыпкин \\ Казанский национальный исследовательский технологический университет, \\ ул. К. Маркса, 68, Казань, 420015 (Россия), e-mail: may62@mail.ru
}

Изучено взаимодействие полимера нитрата целлюлозы с этиловым эфиром $n$-аминобензойной кислоты. В результате физико-химических методов исследования были установлены наиболее вероятные процессы протекания химической реакции, а именно замещение нитратных групп нитрата целлюлозы на радикал этилокси $n$-аминобензоила, раскрытие цикла глюкопиранозы с присоединением к образовавшимся свободным связям фрагмента молекулы этилового эфира $n$-аминобензойной кислоты, деполимеризация макромолекулы нитрата целлюлозы и гидролиз нитратных групп.

Ключевые слова: переработка полимеров; нитрат целлюлозы; этиловый эфир $n$-аминобензойной кислоты; замещение нитратных групп; деструкция макроцепи.

\section{Введение}

Химическая модификация полимеров - одно из основных направлений развития современной химии высокомолекулярных соединений, ярким представителем этого класса является целлюлоза и ее производные. В настоящее время проводится систематическое исследование новых методов химических превращений и модификации свойств целлюлозы и создания новых типов целлюлозных материалов. Полученные результаты дают возможность сделать обобщения и определить некоторые основные направления дальнейшего развития современной химии целлюлозы [1].

Цель данных исследований - разработать способ химической модификации нитратов целлюлозы (НЦ) этилокси $n$-аминобензоилом.

Эфиры $n$-аминобензойной кислоты и их производные, являясь уникальными соединениями по своим биологическим и практически значимым свойствам, до настоящего времени привлекают внимание исследователей всего мира, занимающихся поиском новых биологически активных веществ, что обусловлено их широким применением и синтетическими возможностями [2].

Исследованию работ по химическому превращению нитратов целлюлозы путем этерификации свободных гидроксилов, переэтерификации нитратных групп, нуклеофильному замещению последних посвящено немало работ [3-8]. Их можно получить по реакции замещения нитратных и гидроксильных групп,

Романова Светлана Марсельевна - кандидат химических наук, доцент кафедры инженерной экологии, e-mail: romsvetlana80@mail.ru

Трескова Вера Игоревна - аспирант, e-mail: may62@mail.ru

Гильманов Руслан Замильевич - доктор химических наук, профессор кафедры химии и технологии органических соединений азота,

e-mail: gilmanovrz@kstu.ru

Хузеев Марсель Валиевич - доктор технических наук, профессор кафедры химии и технологии высокомолекулярных соединений.

Засыпкин Алексей Геннадьевич - магистрант, e-mail: donponcho@mail.ru которые приводят к образованию смешанных простых и сложных нитроэфиров целлюлозы.

\section{Экспериментальная часть}

Методы физико-химических исследований ИК-спектры записывают на спектрометре Фурье Avatar-360 с математическим обеспечением «OMNIC» в интервале частот 400-4000 cм

Спектры ЯМР ${ }^{1} \mathrm{H}$ записывают на спектрометpe Bruker MSL-400, $v_{\text {н }}=400$ МГц, (растворитель дейтерированный диметилсульфоксид, внутренний стандарт - $\left.\left(\mathrm{CH}_{3}\right)_{4} \mathrm{Si}\right)$.

\footnotetext{
* Статья имеет электронный дополнительный материал (приложение): DOI: 10.14258/jcprm.1404051s.

** Автор, с которым следует вести переписку.
} 
Для изучения методов дифференциальной сканирующей калориметрии (ДСК) и термогравиметрического анализа (ТГА) использовался модуль TGA/DSC Mettler Toledo, который является компонентом системы термического анализа Star Mettler Toledo. В его состав входят прецизионные весы Mettler Toledo, обеспечивающие измерения изменений массы. Измерения проводят на анализаторе DTA HSS2.

Микроскопическое исследование оптически анизотропных элементов, фазовых элементов и фазовых переходов (плавление и кристаллизация) изучают на поляризационном микроскопе МИН-8.

Относительные величины среднечисленной, средневесовой, средней молекулярных масс и коэффициента полидисперсности определяют методом гельпроникающей хроматографии на хроматографе Viscotec GPC max VE-2001 (растворитель - тетрагидрофуран).

Определение содержания азота нитратных групп проводят ферросульфатным методом [9].

Характеристическую вязкость определяли на вискозиметре ВПЖ-3 (растворитель - ацетон).

Острую токсичность изучали на белых беспородных крысах живой массой 180-200 г, которым однократно внутрижелудочно вводили водную суспензию (20\% в массовых долях) исследуемого вещества в различных дозах. Контрольным животным вводили дистиллированную воду. За подопытными животными вели ежедневные наблюдения в течение 10 суток после введения исследуемых растворов, учитывая клиническую картину интоксикации.

Акарицидную активность оценивают показателем $\mathrm{CK}_{50}$ (среднесмертельная концентрация), которую определяют и рассчитывают согласно методике МУ 3.5.2.1759-03. В опытах на дно одноразовых стерильных чашек Петри помещают фильтровальную бумагу, на которую наносят по 1 мл раствора смешанного азотнокислого эфира целлюлозы, содержащего сульфаниламидные группы, в ацетоне (ГОСТ 2603-79).

Общая методика проведения эксперимента

К раствору 1 г НЦ в 20 мл диметилформамида (ДМФА) добавляли растворенный в 20 мл ДМФА этиловый эфир $n$-аминобензойной кислоты из расчета 3 моль на каждую функциональную группу полимера и перемешивали при заданной температуре $\left(50{ }^{\circ} \mathrm{C}, 80{ }^{\circ} \mathrm{C}\right)$ от 4 до 8 ч. По окончании выдержки реакционную массу высаживали в дистиллированную воду объемом 100 мл. Выпавший твердый продукт отфильтровывали на воронке Шотта, промывали горячей, а потом холодной водой и сушили до постоянной массы сначала на воздухе, затем в вакуум-эксикаторе над хлористым кальцием.

\section{Обсуждение результатов}

Ждановым и сотрудниками [10] были рассчитаны электронные заряды атомов пиранозного кольца молекулы тринитрата целлюлозы, которые дают представление о реакционной способности ее функциональных групп. Наибольшим положительным зарядом в НЦ обладают атомы азота нитратных групп, следовательно, они будут наиболее подвержены атаке нуклеофилом. В результате взаимодействия НЦ с веществами нуклеофильного характера наиболее вероятна атака нуклеофилом, после атомов азота, углеродов в положениях $\mathrm{C}_{1}$ и $\mathrm{C}_{4}$, приводящая к деполимеризации макромолекулы НЦ. Затем атаке нуклеофилом должны подвергаться углеродные атомы $\mathrm{C}_{3}$ и $\mathrm{C}_{5}$, что приводит к замещению гидроксильных и нитратных групп и раскрытию глюкопиранозного цикла соответственно. Далее происходит замещение нитратных групп у углерода $\mathrm{C}_{2}$. И только в последнюю очередь атакуется углерод в положении $\mathrm{C}_{6}$, но данная атака маловероятна.

Группой ученых [11] была исследована реакция взаимодействия нитрата целлюлозы $\mathrm{C}_{6} \mathrm{H}_{7} \mathrm{O}_{2}(\mathrm{OH})_{0,3}\left(\mathrm{ONO}_{2}\right)_{2,7}$. с содержанием азота $11,46 \%$ с калиевой солью $n$-аминобензойной кислоты. Взаимодействие компонентов проводилось при комнатной температуре 72 ч. В результате реакции удалось получить полимер карбоксифениламинонитрат целлюлозы с эмпирической формулой элементарного звена $\mathrm{C}_{6} \mathrm{H}_{7} \mathrm{O}_{2}\left(\mathrm{NO}_{2}\right)_{1,9}(\mathrm{OH})_{0,9}\left(\mathrm{C}_{6} \mathrm{H}_{4} \mathrm{NHCOOH}\right)_{0,6}$. Реакция проходила с гидролизом нитратных групп, их замещением карбоксифениламинным радикалом, раскрытием глюкопиранозного кольца с присоединением по образовавшимся связям карбоксифениламинного радикала. Процесс занимал длительное время, продукт реакции получили с достаточно низкой степенью замещения нитратных групп.

В данной работе для модификации нитрата целлюлозы был предложен этиловый эфир $n$-аминобензойной кислоты, который является хорошим нуклеофильным агентом, так как наличие в ароматическом кольце электродонорных заместителей, то есть алкильных групп, увеличивает его основность среди ароматических аминов [12].

В работе использовали НЦ с эмпирической формулой $\mathrm{C}_{6} \mathrm{H}_{7} \mathrm{O}_{2}(\mathrm{OH})_{0,46}\left(\mathrm{ONO}_{2}\right)_{2,54}$, с содержанием азота $\mathrm{N}=12,23 \%$. Химическое превращение НЦ осуществлялось в гомогенной среде диметилформамида, который хорошо растворяет исходные компоненты и остается индифферентным по отношению к ним. 
Реакцию химического взаимодействия НЦ с этилокси $n$-аминобензоилом вели при температурах 50 и $80{ }^{\circ} \mathrm{C}$ и времени выдержки 4, 6 и 8 ч, так как при низких температурах реакция идет с малой интенсивностью, а при температурах выше $80{ }^{\circ} \mathrm{C}$ идет термический распад структуры макромолекулы НЦ [13]. Синтез осуществляли в соотношении 1 моля этилового эфира этилокси $n$-аминобензоила на каждую функциональную группу элементарного звена НЦ (см. табл.).

Синтезированные сложные эфиры целлюлозы представляют собой порошки белого цвета, хорошо растворимые в диметилформамиде, диметилсульфоксиде, ацетоне, этилацетате и других полярных растворителях.

На основании экспериментально определенных значений содержания элементов С, H, N в продуктах взаимодействия и результатов физико-химических исследований были рассчитаны эмпирические формулы элементарного звена полимеров, приведенные в таблице.

При взаимодействии НЦ с этиловым эфиром $n$-аминобензойной кислоты при температуре $50{ }^{\circ} \mathrm{C}$ в течение 4 ч в полимере происходило уменьшение количества нитратных групп, степень их замещения на фрагмент нуклеофила составила $\gamma=0,63$. С целью интенсификации процесса замещения функциональных групп нитрата целлюлозы на фрагмент этилбензоксиамина были увеличены температура реакционной среды и время реакции. В полученном при температуре реакции $80{ }^{\circ} \mathrm{C}$ и времени выдержки 8 ч полимере $\mathrm{C}_{6} \mathrm{H}_{7} \mathrm{O}_{2}(\mathrm{OH})_{0,98}\left(\mathrm{C}_{6} \mathrm{H}_{4} \mathrm{NHCOOC}_{2} \mathrm{H}_{5}\right)_{1,37}\left(\mathrm{ONO}_{2}\right)_{0,65}$ степень замещения увеличилась до 1,37. Таким образом, было установлено, что с увеличением температуры реакционной среды прямо пропорционально происходит увеличение степени замещения нитратных групп на фрагмент $\mathrm{C}_{6} \mathrm{H}_{4} \mathrm{NHCOOC}_{2} \mathrm{H}_{5}$. Однако при увеличении температуры реакции свыше $80{ }^{\circ} \mathrm{C}$ гидролитические и деполимеризационные процессы становятся доминирующими [13] (табл.).

Для полученных полимеров характерны следующие полосы поглощения в инфракрасном спектре [14]: идентифицируются полосы валентных и деформационных колебаний связей $\mathrm{CH}_{2}-\mathrm{NO}_{2}$ при 700, 800, $1290,1300,1320,1680,1070$ cм$^{-1}$ - соответствующие колебаниям простой эфирной связи; деформация полос, характерная для колебания глюкопиранозного кольца, в области 1060-1160 см-1 не наблюдается, это говорит о том, что процессы деполимеризации и раскрытия цикла идут, но незначительно. Возрастают пики, характерные для колебания -ОН групп - $3500 \mathrm{~cm}^{-1}$, но появляется плечо при $3300 \mathrm{~cm}^{-1}$, что характерно для колебания связанных -NH групп (вторичные амины).

Появляются новые полосы поглощения: плечо при $1580 \mathrm{~cm}^{-1}$, что характерно для колебания связи -C-N, полоса $1206 \mathrm{~cm}^{-1}$ соответствует симметричным колебаниям сложной эфирной связи, полоса $1380 \mathrm{~cm}^{-1}$ соответствует колебанию связи - $\mathrm{CH}_{2}$, полоса $1455 \mathrm{~cm}^{-1}$ характерна для колебания связи $-\mathrm{CH}_{3}$.

В спектрах ЯМР ${ }^{1} \mathrm{H}$ синтезированных продуктов присутствуют сигналы, соответствующие протонам растворителя 3,33 и 2,50. Отмечены сигналы глюкопиранозного кольца (м. д.): $5,75\left({ }^{3} \mathrm{H}\right), 5,15\left({ }^{2,4} \mathrm{H}\right), 4,8$ $\left({ }^{6} \mathrm{H}\right), 4,1\left({ }^{1,5} \mathrm{H}\right)$. Наличие в составе полученного полимера фрагмента бензольного кольца было доказано спектрами ЯМР ${ }^{1} \mathrm{H}$, которые проявляются в области 7,95 м.д., сигнал в области 1,26 м.д. отнесен к протонам сложноэфирной группы, сигнал 3,25 - к протону группы -О-CH-, протоны - $\mathrm{CH}_{2}$ и $-\mathrm{CH}_{3}$ проявляются при значении 4,62 и 4,56 м.д. Сигналы NH-группы проявляются в области 2,46 м.д. Протоны CH-N проявляются в области 2,88 и 2,73 м.д. [15].

Результаты реакций взаимодействия НЦ с этиловым эфиром $n$-аминобензойной кислоты

\begin{tabular}{|c|c|c|c|c|c|c|c|c|c|c|c|c|c|}
\hline \multirow{3}{*}{ № } & \multicolumn{2}{|c|}{$\begin{array}{l}\text { Условия } \\
\text { реакции }\end{array}$} & \multirow{3}{*}{ 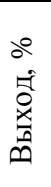 } & \multirow{3}{*}{ 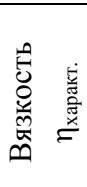 } & \multirow{3}{*}{$\begin{array}{l}\text { U } \\
\text { 魚 } \\
\text { 狊 } \\
ت\end{array}$} & \multirow{3}{*}{ 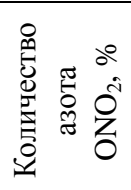 } & \multicolumn{7}{|c|}{ Элементный анализ } \\
\hline & \multirow{2}{*}{ 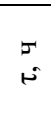 } & \multirow{2}{*}{$\begin{array}{l}0 \\
+ \\
-\end{array}$} & & & & & Вы & ислен & $\%$ & \multirow{2}{*}{ Брутто формула } & \multicolumn{3}{|c|}{ Найдено, \% } \\
\hline & & & & & & & $\mathrm{C}$ & $\mathrm{H}$ & $\mathrm{N}$ & & $\mathrm{C}$ & $\mathrm{H}$ & $\mathrm{N}$ \\
\hline Исх. & - & - & - & 1,50 & 195 & 12,23 & 26,23 & 2,72 & 12,96 & $\mathrm{C}_{6} \mathrm{H}_{7} \mathrm{O}_{2}(\mathrm{OH})_{0,46}\left(\mathrm{ONO}_{2}\right)_{2,54}$ & 25,65 & 2,96 & 12,23 \\
\hline 1 & 4 & 50 & 95 & 1,5 & 218 & 7,52 & 39,80 & 4,17 & 10,18 & $\begin{array}{l}\mathrm{C}_{6} \mathrm{H}_{7} \mathrm{O}_{2}(\mathrm{OH})_{0,58}\left(\mathrm{C}_{6} \mathrm{H}_{4} \mathrm{NH}\right. \\
\left.\mathrm{COOC}_{2} \mathrm{H}_{5}\right)_{0,63}\left(\mathrm{ONO}_{2}\right)_{1,79}\end{array}$ & 39,65 & 4,03 & 10,00 \\
\hline 2 & 6 & 50 & 92 & 1,45 & 216 & 5,46 & 44,94 & 4,72 & 9,11 & $\begin{array}{l}\mathrm{C}_{6} \mathrm{H}_{7} \mathrm{O}_{2}(\mathrm{OH})_{0,65}\left(\mathrm{C}_{6} \mathrm{H}_{4} \mathrm{NH}\right. \\
\left.\mathrm{COOC}_{2} \mathrm{H}_{5}\right)_{0,94}\left(\mathrm{ONO}_{2}\right)_{1,41}\end{array}$ & 44,01 & 4,54 & 8,89 \\
\hline 3 & 8 & 50 & 89 & 1,37 & 215 & 4,12 & 48,25 & 5,08 & 8,40 & $\begin{array}{l}\mathrm{C}_{6} \mathrm{H}_{7} \mathrm{O}_{2}(\mathrm{OH})_{0,72}\left(\mathrm{C}_{6} \mathrm{H}_{4} \mathrm{NH}\right. \\
\left.\mathrm{COOC}_{2} \mathrm{H}_{5}\right)_{1,16}\left(\mathrm{ONO}_{2}\right)_{1,12}\end{array}$ & 47,87 & 4,98 & 8,22 \\
\hline 4 & 4 & 80 & 85 & 1,27 & 219 & 4,71 & 46,88 & 4,92 & 8,77 & $\begin{array}{l}\mathrm{C}_{6} \mathrm{H}_{7} \mathrm{O}_{2}(\mathrm{OH})_{0,64}\left(\mathrm{C}_{6} \mathrm{H}_{4} \mathrm{NH}\right. \\
\left.\mathrm{COOC}_{2} \mathrm{H}_{5}\right)_{1,09}\left(\mathrm{ONO}_{2}\right)_{1,27}\end{array}$ & 46,11 & 4,55 & 8,48 \\
\hline 5 & 6 & 80 & 80 & 1,19 & 216 & 3,41 & 49,89 & 5,28 & 7,97 & $\begin{array}{l}\mathrm{C}_{6} \mathrm{H}_{7} \mathrm{O}_{2}(\mathrm{OH})_{0,81}\left(\mathrm{C}_{6} \mathrm{H}_{4} \mathrm{NH}\right. \\
\left.\mathrm{COOC}_{2} \mathrm{H}_{5}\right)_{1,25}\left(\mathrm{ONO}_{2}\right)_{0,94}\end{array}$ & 49,02 & 5,10 & 7,58 \\
\hline 6 & 8 & 80 & 76 & 1,12 & 214 & 2,34 & 52,36 & 5,58 & 7,28 & $\begin{array}{l}\mathrm{C}_{6} \mathrm{H}_{7} \mathrm{O}_{2}(\mathrm{OH})_{0,98}\left(\mathrm{C}_{6} \mathrm{H}_{4} \mathrm{NH}\right. \\
\left.\mathrm{COOC}_{2} \mathrm{H}_{5}\right)_{1,37}\left(\mathrm{ONO}_{2}\right)_{0,65}\end{array}$ & 51,95 & 5,39 & 7,02 \\
\hline
\end{tabular}


При температурах свыше $60{ }^{\circ} \mathrm{C}$ эфирная связь этилового эфира $n$-аминобензойной кислоты будет разрушаться с отщеплением этоксильного радикала и будет образовываться карбоксильная группа, которая впоследствии вступает в реакцию комплексообразования с ДМФА, что качественно подтверждается реакцией соляной кислоты и нитрита натрия.

Методом дифференциальной сканирующей калориметрии и термогравиметрического анализа были сняты кривые нагревания. ТГА позволяет получить количественную информацию об изменении массы образца в процессе его нагревания. Наибольшая убыль массы образца плавления $\mathrm{C}_{6} \mathrm{H}_{7} \mathrm{O}_{2}(\mathrm{OH})_{0,98}\left(\mathrm{C}_{6} \mathrm{H}_{4} \mathrm{NHCOOC}_{2} \mathrm{H}_{5}\right)_{1,37}\left(\mathrm{ONO}_{2}\right)_{0,65}$ синтезированного полимера наблюдается при температуре $210,5^{\circ} \mathrm{C}$. Данная точка характеризует температуру его плавления. Дифференциальная сканирующая калориметрия базируется на принципе Боэрсма [16], или принципе теплового потока, в соответствии с которым осуществляется сравнение тепловых потоков образца и контрольного измерения. На кривой ДСК температура максимума пика для полимеров характеризует среднюю температуру плавления кристаллитов. ДСК является методом изучения фазовых переходов в полимерных материалах. На кривых ДСК исходного НЦ и модификата, полученного при взаимодействии НЦ с этилокси $n$-аминобензоилом при $80{ }^{\circ} \mathrm{C}$ и 8 ч, наблюдается только один пик, характерный только для процесса разложения, так как температура стеклования имеет более высокое значение. Кривая ДСК очень чувствительна к химическому составу анализируемого вещества. Ширина пика характеризует наличие в составе образца примесей. Ширина пика исходного НЦ и $\mathrm{C}_{6} \mathrm{H}_{7} \mathrm{O}_{2}(\mathrm{OH})_{0,98}\left(\mathrm{C}_{6} \mathrm{H}_{4} \mathrm{NHCOOC}_{2} \mathrm{H}_{5}\right)_{1,37}\left(\mathrm{ONO}_{2}\right)_{0,65}$ модификата находится в одних пределах, 3,08 и 5,01 ${ }^{\circ} \mathrm{C}$ соответственно, это говорит о том, что в результате взаимодействия НЦ с этиловым эфиром $n$-аминобензойной кислоты было синтезировано химическое соединение, а не механическая смесь.

Данные термической поляризационной микроскопии показали, что в интервале температур 215$220{ }^{\circ} \mathrm{C}$ происходит плавление продуктов с последующим разложением, а при достижении более высоких температур происходит их обугливание. Температура плавления модификатов, по сравнению с исходным НЦ (температура плавления $195^{\circ} \mathrm{C}$ ), сдвинулась в сторону более высоких температур.

Изучение процесса деполимеризации эфиров целлюлозы проводят с использованием данных характеристической вязкости растворов полимера и молекулярно-массового распределения до и после химической модификации. Изучение закономерностей изменения вязкости показало, что вязкость растворов полученных продуктов снижается незначительно по сравнению с вязкостью исходного нитрата целлюлозы. Вязкость у раствора полимера $\mathrm{C}_{6} \mathrm{H}_{7} \mathrm{O}_{2}(\mathrm{OH})_{0,98}\left(\mathrm{C}_{6} \mathrm{H}_{4} \mathrm{NHCOOC}_{2} \mathrm{H}_{5}\right)_{1,37}\left(\mathrm{ONO}_{2}\right)_{0,65}$, полученного при 8 ч и при температуре $80{ }^{\circ} \mathrm{C}$, по сравнению с вязкостью исходной НЦ $\eta_{\text {характ. }}=1,5$, снизилось до $\eta_{\text {характ. }}=1,12$ (табл.). Это говорит о том, что процесс деполимеризации макромолекулы происходит несущественно. Вследствие пространственных затруднений происходит стабилизация отрицательного заряда атома азота в молекуле этилового эфира $n$-аминобензойной кислоты [12], за счет этого снижается степень деполимеризации макромолекулы нитрата целлюлозы в реакции нуклеофильного замещения с этилокси $n$-аминобензоилом. Уменьшение времени истечения ацетоновых растворов продуктов модификации по сравнению с исходным нитратом целлюлозы говорит об уменьшении молекулярной массы полученных полимеров, но значение характеристической вязкости растворов свидетельствует только об относительном изменении молекулярной массы и не позволяет получить молекулярно-массовые характеристики полимеров.

Для определения средней молекулярной массы смешанных сложных эфиров целлюлозы и других молекулярно-массовых характеристик использовался метод гельпроникающей хроматографии, который позволяет проводить фракционирование высокомолекулярных соединений по молекулярным массам. Средневесовая молекулярная масса нитрата целлюлозы $\overline{M_{\omega}}=25428$ (стирольный эквивалент) превышает значение средневесовой молекулярной массы всех синтезированных образцов, средневесовая масса образца $\left(8\right.$ ч, $\left.80^{\circ} \mathrm{C}\right) \overline{M_{\omega}}=15981$, это также доказывает идущие несущественные деполимеризационные процессы в реакции. На фоне протекания деполимеризационных процессов происходит повышение однородности молекулярно-массового состава. Если коэффициент полидисперсности образца НЦ 4,51, то коэффициент полидисперсности синтезированных соединений меньше, для модификата (8 ч, $\left.80{ }^{\circ} \mathrm{C}\right)$ он равен 3,467 . Чем меньше полидисперсность полимера, тем уже дисперсия значений его свойств и тем определеннее его технологические и эксплуатационные характеристики.

На основании элементного анализа, данных ИК, ЯМР ${ }^{1} \mathrm{H}$ спектроскопии, хроматографических анализов, результатов качественных и количественных реакций были предложены направления протекания процесса: 

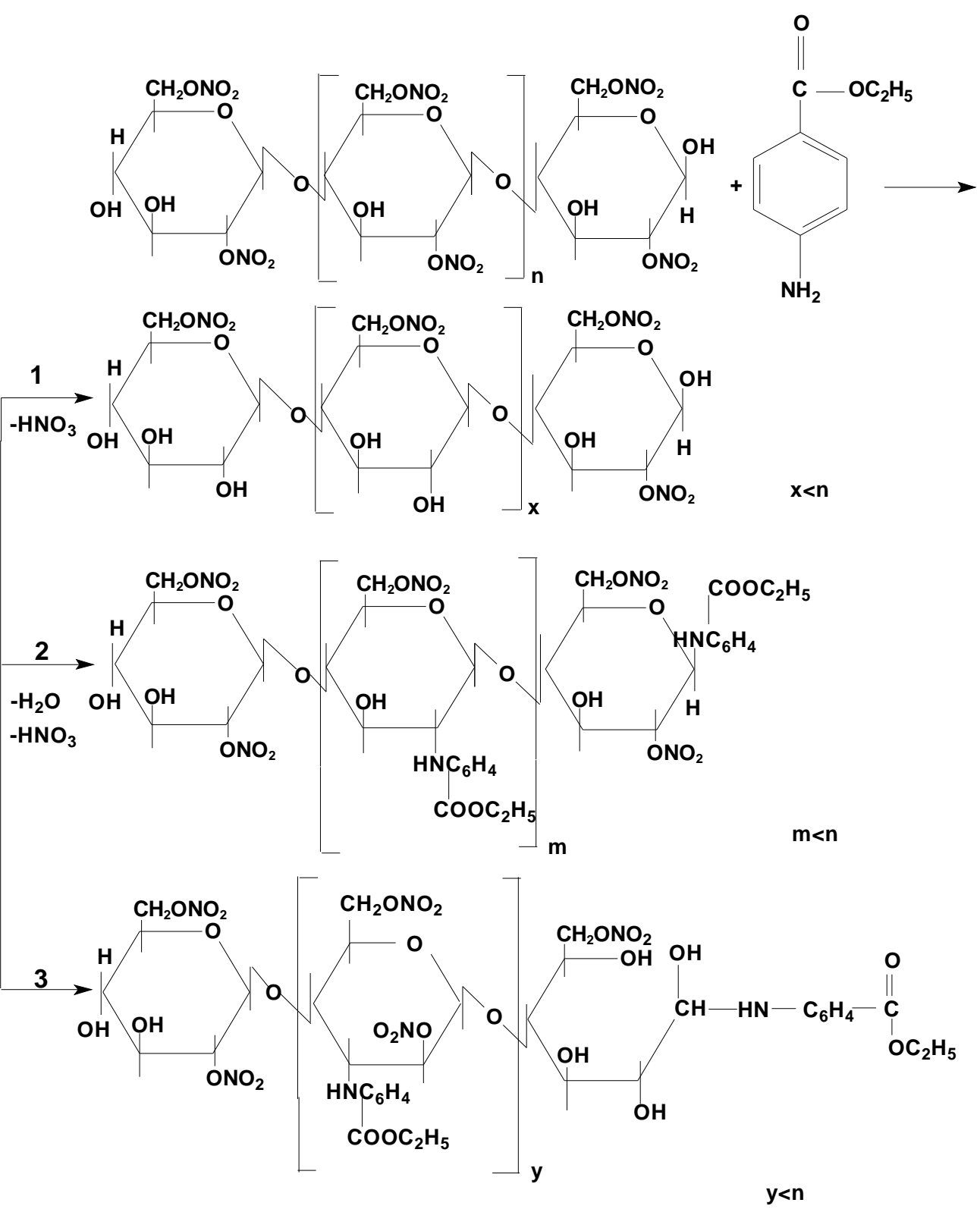

Схема реакции взаимодействия нитрата целлюлозы с этиловым эфиром $n$-аминобензойной кислоты: 1 - гидролиз нитратных групп и деполимеризация, 2 - замещение нитратных и гидроксильных групп на радикал этилового эфира $n$-аминобензойной кислоты, 3 - раскрытие глюкопиранозного кольца НЦ с присоединением по концам радикала этилового эфира $n$-аминобензойной кислоты

Таким образом, химическая модификация НЦ под воздействием этилового эфира $n$-аминобензойной кислоты в среде ДМФА происходит за счет одновременного протекания нескольких процессов. С повышением температуры происходит гидролиз нитратных групп с последующим замещением гидроксильных и нитратных групп на радикал этилового эфира $n$-аминобензойной кислоты, разрыв полимерных цепей по $\beta$-глюкозидной связи, раскрытие цикла глюкопиранозы с присоединением к образовавшимся свободным связям фрагмента молекулы этилового эфира $n$-аминобензойной кислоты.

Для сложного смешанного эфира целлюлозы со структурной формулой $\mathrm{C}_{6} \mathrm{H}_{7} \mathrm{O}_{2}(\mathrm{OH})_{0,98}\left(\mathrm{C}_{6} \mathrm{H}_{4} \mathrm{NHOOC}_{2} \mathrm{H}_{5}\right)_{1,37}\left(\mathrm{ONO}_{2}\right)_{0,65}$ проведены исследования по изучению острой токсичности и акарицидной активности. Среднесмертельная концентрация $\mathrm{CK}_{50}$ составляет $0,0410 \%$ масс., следовательно, этилбензоксиаминонитрат целлюлозы проявляет среднюю акарицидную активность против клещей рода Psoroptes cuniculi. При изучении острой токсичности этилбензоксиаминонитрата целлюлозы летальная 
доза ЛД ${ }_{50}$ составила 5500 мг/кг, что дает основание для отнесения данного вещества к IV классу опасности (малоопасные).

В результате химического воздействия на НЦ этилового эфира $n$-аминобензойной кислоты изменяется структура полимера и его свойства, значительно уменьшается количество нитратных групп, понижается горючесть по сравнению с исходным нитратом целлюлозы и приобретается биологическая активность. Синтезированный этилбензоксиаминонитрат целлюлозы после дополнительных исследований можно рекомендовать в качестве активного и/или вспомогательного вещества в технологии лекарственных форм, что может послужить основой для разработки системы безотходного жизненного цикла нитратцеллюлозных порохов.

\section{Электронный дополнительный материал}

В электронном приложении к статье приведены ИК-спектры исходного нитрата целлюлозы и этилбензоксиаминонитрата целлюлозы, ЯМР-спектры исходного нитрата целлюлозы и этилбензоксиаминонитрата целлюлозы, кривые нагревания ДСК и ТГА для исходного нитрата целлюлозы и этилбензоксиаминонитрата целлюлозы, выходные данные ДСК и ТГА исходного нитрата целлюлозы и этилбензоксиаминонитрата целлюлозы.

\section{Список литературь}

1. Роговин 3.А. Химические превращения и модификация целлюлозы. М., 1967. 176 с.

2. Синтез, строение и свойства новых полифункциональных производных $n$-аминобензойной кислоты [Электронный ресурc]. URL: http://avtoreferats.com/article/view/id/14098

3. Сарыбаева Р.И., Щелокова Л.С. Химия азотнокислых эфиров целлюлозы. Фрунзе, 1985. 164 с.

4. Мойсак М.Е. Химия и технология нитроцеллюлозы. М., 1941. 271 с.

5. Романова С.М., Мадякина А.М., Фридланд С.В. Модифицирование азотнокислых эфиров целлюлозы несимметричным гидразином и его гидразидами // Известия вузов. Химия и хим. технология. 2012. Т. 55. №3. C. $68-73$.

6. Романова С.М., Мадякина А.М., Фатыхова Л.А., Фридланд С.В. Алкоксилирование нитратов целлюлозы // Журнал органической химии. 2013. Т. 83. № 1. С. 65-69.

7. Романова С.М., Трескова В.И., Гильманов Р.З. Химическая модификация азотнокислых эфиров целлюлозы аминопроизводными пиридина // Вестник КТУ. 2012. Т. 15. №14. С. 67-70.

8. Романова С.М., Трескова В.И., Гильманов Р.3. Пути рекуперации устаревших нитратов целлюлозы солями пиридина // Вестник КТУ. Т. 16. №4. С. 124-128.

9. Simeček I. Stanoveni organickych Siranem Zelezhatum // Chem. Prumyst. 1957. Sv. 7. N 6. S. 285-289.

10. Zhdanov Yu. A., Minkin V.Z., Ostroumov Y.A. Conformational preferences of treenitrat cellulose // Carbohyd Res. 1968. Vol. 7. Pp. 156-160.

11. Нургатин В.В., Фридланд С.В., Степанова Н.В. Возможные пуги переработки изделий на основе нитратов целлюлозы // Вестник Татарского отделения Российской экологической академии. 2000. №3. С. 50-54.

12. Травень В.Ф. Органическая химия: учебник для вузов: в 2 т. М., 2005. 582 с.

13. Коршак В.В. Синтез полимеров методами модификации // Успехи химии. 1980. Вып. 12. С. 2286-2313.

14. Беллами Л. Инфракрасные спектры сложных молекул. М., 1963. 592 с.

15. Ионин Б.И., Ершов Б.А., Кольцов А.И. ЯМР спектроскопия в органической химии. Л.: Химия, 1983. 272 с.

16. Boersma J., Yakubovich S.B. The asymptotic sum of a Kapteyn series // SIAM Rev. 1998. Vol. 40. Pp. 986-990.

Поступило в редакичию 14 февраля 20142. После переработки 7 апреля 2014 г. 
Romanova S.M., Treskova V.I. , Gil'manov R.Z., Huzeev M.V., Zasypkin A.G. SYNTHESIS OF NEW POLYMERS BASED ON CELLULOSE NITRATE

Kazan State Technological University, ul. Karla Marxa, 68, Kazan, 420015 (Russia), e-mail: may62@mail.ru

Studied in the paper is the interaction of the polymer cellulose nitrate with ethyl $p$-amino benzoic acid. As a result of physical and chemical methods of investigation were the most likely set of chemical reaction processes, namely the substitution of nitrate groups on cellulose nitrate radical ethyloxy $p$-aminobenzoila, glucopyranose ring opening of accession to free relations formed part of the molecule of ethyl $p$-aminobenzoic acid depolymerization of macromolecules of cellulose nitrate and hydrolyzing the nitrate groups. struction

Keywords: Plastics Processing, cellulose nitrate, ethyl p-aminobenzoic acid, substitution nitrate groups; macrochain de-

\section{References}

1. Rogovin Z.A. Himicheskie prevrashhenija i modifikacija celljulozy. [Chemical transformation and modification of cellulose]. Moscow, 1967, 176 p. (in Russ.).

2. Sintez, stroenie i svojstva novyh polifunkcional'nyh proizvodnyh p-aminobenzojnoj kisloty. [Synthesis, structure and properties of new polyfunctional derivatives of p-aminobenzoic acid] [Electronic resource]. URL: http://avtoreferats.com/article/view/id/14098 (in Russ.).

3. Sarybaeva R.I., Shhelokova L.S. Himija azotnokislyh jefirov celljulozy. [Chemistry nitrate cellulose ethers]. Frunze, 1985, 164 p. (in Russ.).

4. Mojsak M.E. Himija i tehnologija nitrocelljulozy. [Chemistry and Technology of nitrocellulose]. Moscow, 1941, 271 p. (in Russ.).

5. Romanova S.M., Madjakina A.M., Fridland S.V. Izvestija vuzov. Himija i himicheskaja tehnologija. 2012, vol. 55, no. 3, pp. 68-73. (in Russ.).

6. Romanova S.M., Madjakina A.M., Fatyhova L.A., Fridland S.V. Zhurnal obshhej himii, 2013, vol. 83, no. 1, pp. 65-69. (in Russ.).

7. Romanova S.M., Treskova V.I., Gil'manov R.Z. Vestnik KTU, 2012, vol. 15, no. 14, pp. 67-70. (in Russ.).

8. Romanova S.M., Treskova V.I., Gil'manov R.Z. Vestnik KTU, vol. 16, no. 4, pp. 124-128. (in Russ.).

9. Simeček I. Chem. Prumyst, 1957, vol. 7, no. 6, pp. 285-289. (in Czech.).

10. Zhdanov Yu. A., Minkin V.Z., Ostroumov Y.A. Carbohyd Res. 1968, vol. 7, pp. 156-160.

11. Nurgatin V.V., Fridland S.V., Stepanova N.V. Vestnik Tatarskogo otdelenija Rossijskoj jekologicheskoj Akademii, 2000, no. 3, pp. 50-54. (in Russ.).

12. Traven' V.F. Organicheskaja himija: uchebnik dlja vuzov: $v 2$ t. [Organic chemistry: textbook for high schools: $v 2$ vol.]. Moscow, 2005, 582 p. (in Russ.).

13. Korshak V.V. Uspehi himii. 1980, no. 12, pp. 2286-2313. (in Russ.).

14. Bellami L. Infrakrasnye spektry slozhnyh molekul. [Infrared spectra of complex molecules]. Moscow, 1963, 592 p. (in Russ.).

15. Ionin B.I., Ershov B.A., Kol'cov A.I. JaMR spektroskopija v organicheskoj himii. [NMR spectroscopy in organic chemistry]. Leningrad, 1983, 272 p. (in Russ.).

16. Boersma J., Yakubovich S.B. SIAM Rev. 1998, vol. 40, pp. 986-990.

Received February 14, 2014

Revised April 7, 2014

\footnotetext{
* Corresponding author.
} 
